\title{
Design optimization algorithm for plate heat exchanger
}

\author{
Harshal Khond ${ }^{+*}$, Dilpak Saurabh P. ${ }^{\dagger}$ and Kundalik V. Mali ${ }^{\dagger}$ \\ †Post Graduate Student, Mechanical Engg. Department, MAEER's MIT College of Engineering, Savitribai Phule Pune University, Pune, India
}

Accepted 03 March 2016, Available online 15 March 2016, Special Issue-4 (March 2016)

\begin{abstract}
As there are a large number of variables affecting the performance of the plate heat exchanger and its complex geometry, the design of these types of heat exchangers is difficult. Unlike other types of heat exchanger on which design procedure data is available, the designing of plate heat exchanger is a monopoly of certain manufacturing companies. This makes the problem worse. The objective of this paper is to optimize the design of plate heat exchanger by reducing its number of plates. A simple mathematical model is introduced to achieve it. Also a program was defined for determining the optimal solution based on the mathematical model for given operational constraints. The model determines the pressure drop and heat capacity of a plate heat exchanger in single and multipass state. The optimal solution is compared to the answers of CAS200 commercial software. The results show that the effect of the start plates, end plates and transverse distribution in optimal solution is considerable.
\end{abstract}

Keywords: Plate heat exchanger, mathematical model, algorithm, optimization

\section{Introduction}

Today, food, pharmaceutical and chemical industries widely use heat exchangers, so selection of an appropriate heat exchanger is one of the major concerns of today's engineering industry. These heat exchangers not only must be able to meet the needs of the process but also must be low in maintenance and operating costs. Shell and tube heat exchangers have been used for many years, but, in the past decade, the demand for plate heat exchanger (PHE) has increased.

Compared to other heat exchangers plate heat exchangers have positive features like higher compression ratio, less total cost, less sediment, and flexibility of the change of heat transfer surfaces which results in an increasing tendency toward PHEs. Due to variation in PHEs design that can be suitable for different thermal tasks, the design of such heat exchangers is very specialized, and manufacturers of PHEs utilize elaborated computer design techniques. The main characteristic of PHE design is the fact that the number of different plates gives the conditions required for the heat transfer process. As the required heat transfer area is a function of plate type, number of passes, and composition of plates with different corrugations pattern; determination of optimal solution having the minimum possible heat transfer area is complex.

The common methods for designing a PHE and methods to establish a connection between heat

*Corresponding author: Harshal Khond transfer and pressure drop were presented by Shah and Wanniarachchi. But effective parameters were not mentioned in these methods. Due to the complexity of optimization of PHE determination of optimal pattern of 2 Advances in Mechanical Engineering plates is difficult. The effect of the plate pattern's angle on thermo-hydraulic performance of plate heat exchanger was examined by Focke et al. The impact of other effective parameters on the heat capacity, flow distribution in plate heat exchanger (PHE), was represented by Prabhakara Rao et al. The major problem in this model is that the effect of distribution is sensitive to the axial dispersive Peclet number and plate numbers. The performance of PHE, simultaneous optimization of both energy and heat transfer area for thermal integration in multi-stream PHE model, was performed by Yee et al. The optimal design of PHE which does not contain many trials was offered by Wang and Sund'en. It was done in two cases, namely, with and without taking pressure drop determination into account. Park et al. presented numerical work in the field of optimization of PHEs. In 2004,Gut and Pinto published a screening method for selecting optimal configuration of PHEs and later a general method for the optimal design of plate heat exchangers (PHEs) was presented by Kanaris et al. in which a CFD code has been utilized to estimate the heat transmission rate and pressure drop.

Gasket failure is one of the most common problems which happens due to high operating temperature. Hajmohammadi et al. in recent studies investigated the effect of plate thickness on the peak temperature. 
The efficient area of heat transfer is a key parameter in the design and selection process of heat exchangers which is calculated based on the heat load. The allowed pressure drop for determining efficient area of desired heat transfer is the economical design of heat exchanger. In general, designing of a PHE is based on trial and error method. For this purpose, first, the efficient area of heat transfer is to be obtained, and then based on this selection the PHE pressure drop is calculated. The design will be acceptable if this value is less than or equal to the allowable pressure drop or else it is redesigned. The objective of this paper is to develop a new algorithm based on mathematical model to optimize the design of plate heat exchanger by reducing its number of plate, based on specific inputs such as maximum pressure drop and required heat transfer. Although at times it is required to optimize fluid flow and/or heat transfer in which entropy generation minimization (EGM) method is used tofind optimum fluid flow and/or heat transfer characteristics. In the end, the results of the program for a series of Alfa Laval heat exchangers (M3, M6, and M6M) are studied.

\section{Mathematical Model of Plate Heat Exchanger}

A mathematical model is required to investigate the performance of different options in order to choose the correct selection of PHE. The best option is to select according to data available in the commercial plates.

Following hypothesis is used for determination of mathematical model for plate heat exchangers .

1) No phase change occurred in flows.

2) The number of heat transfer plates is enough so that heat transfer conditions for the end plates and on edge of pass plates are of difference with other plates.

3) Flow misdistribution in collectors can be neglected.

4) In the collector, each channel of flow is mixed thoroughly together.

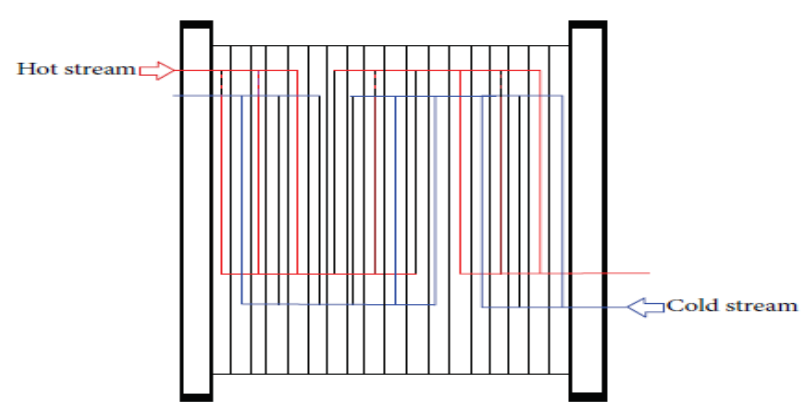

Figure 1: passing flow through a multi pass PHE.

Consider a multi-pass PHE as shown in Figure 1, to explain the mathematical model of the PHE. The multiple-pass PHE in this figure can be divided into several single-pass PHEs, with regards to the above conditions. The number of the PHEs is equal to multiplication of the pass between the hot and the cold Hence the PHE in Figure 1 can be divided into nine single-pass PHEs (Figure 2) as both hot and cold flows have three passes $\left(X_{1}=3, X_{2}=3\right)$.The area of heat transfer of each of these blocks is equal to $\mathrm{S}_{\mathrm{b}}=\mathrm{S} /\left(X_{1} X_{2}\right)$, where $\mathrm{S}$ is total area of heat exchanger.

The number of transfer units (NTU) for each of the heat exchangers is calculated by

$N T U=\frac{U_{b} S_{b} X_{2}}{G_{1} c_{1}}$

Where $U_{b}$ is heat transfer coefficient $(\mathrm{W} / \mathrm{m} 2 \cdot \mathrm{K}), \mathrm{G}_{1}$ is hot fluid mass flow $(\mathrm{kg} / \mathrm{s})$, and $c_{1}$ is specific heat capacity of hot fluid( $\mathrm{j} / \mathrm{kg} \cdot \mathrm{K})$.

Assuming that $\mathrm{R}_{\mathrm{b}}=\mathrm{G}_{1}\left(c_{1} / X_{2}\right) / \mathrm{G}_{1}\left(c_{1 /} \mathrm{X}_{2}\right)<1$, then block heat exchange effectiveness $\varepsilon_{b}$ for parallel flow heat exchanger,

$\varepsilon_{b}=\frac{1-\exp \left(-N T U_{b} \times\left(1+R_{b}\right)\right)}{1+R_{b}}$

And for counter flow heat exchanger,

$\varepsilon_{b}=\frac{1-\exp \left(-N T U_{b} \times\left(1-R_{b}\right)\right)}{1+R_{b} \times \exp \left(-N T U_{b} \times\left(1-R_{b}\right)\right)}$

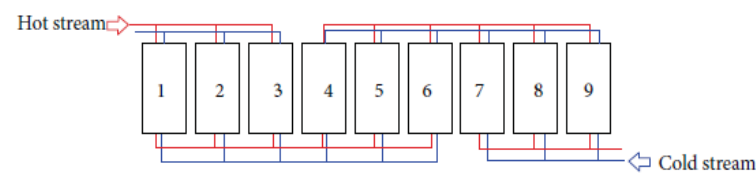

Figure 2: The change of a multi pass to a single-pass PHE

In these relations,

$\varepsilon_{b}=\frac{\delta T_{i}}{\Delta T_{i}}$

Where $\delta T i$ denotes the changes of hot fluid temperature in each block $(\mathrm{K})$ and $\Delta T i$ is the maximum possible temperature change of the fluid $(\mathrm{K})$.

The above relations at $\mathrm{R}_{\mathrm{b}}>1$ are also true; but their physical meanings are different. Therefore, a mathematical model can be achieved in which the temperature change is a function of $U_{b}$ and $S_{b}$ by using the above relations.

An equation can be driven for each of the blocks (single-pass PHE) so that it can relate changes in fluid temperature at each of them to the temperature of the fluid of other blocks.

Consider Block 1 in Figure 2 as an example. Here maximum possible temperature change is equal to difference between initial temperature difference $(\Delta)$ and increase rate of cold fluid temperature to Block 1; it can be shown as the following equation:

$\Delta T_{1}=\frac{R_{b} \times \delta T_{4}+R_{b} \times \delta T_{5}+R_{b} \times \delta T_{6}}{3}$

$-\frac{R_{b} \times \delta T_{7}+R_{b} \times \delta T_{8}+R_{b} \times \delta T_{9}}{3}$ 
As we have,

$$
\varepsilon_{b}=\frac{\delta T_{i}}{\Delta T_{i}}
$$$$
\delta T_{1}=\varepsilon_{b 1} \Delta-\frac{c_{b 1}}{3} * R_{b} * \delta T_{4}-\frac{c_{b 1}}{3} * R_{b} * \delta T_{5}
$$$$
-\frac{c_{b 1}}{3} * R_{b} * \delta T_{6}-\frac{c_{b 1}}{3} * R_{b} * \delta T_{7}
$$$$
-\frac{c_{b 1}}{3} * R_{b} * \delta T_{8}-\frac{c_{b 1}}{3} * R_{b} * \delta T_{9}
$$

These equations can be written for the other blocks, and, in fact, a linear system of equations is obtained which can be solved by determining the changes in temperature of each block. In the general case, the coefficient matrix can be expressed as follows:

$$
[Z]\left[\delta T_{1}\right]=\left[\varepsilon_{b i} \Delta\right]
$$

These systems of equation have been created for the number of passes up to $X 1=7$ and $X 2=6$, with an overall counter flow arrangement. After solving the above system of equations, the following series can be used to obtain changes in temperature of fluids:

$Z_{i j}= \begin{cases}\frac{\varepsilon_{b} R_{b}}{2 X_{1}}\left\{Z_{1}\right\}, & \text { if } j>i \\ 1, & \text { if } j=i \\ \frac{\varepsilon_{b i}}{2 X_{2}}, & \text { if } j<i\end{cases}$

Where

$$
\begin{aligned}
& Z_{1}=1 * \operatorname{sign}\left(j-\left(\operatorname{int}\left[\frac{i-1}{X_{1}}\right]+1\right) X_{1}+0.5\right)+1 \\
& Z_{2}=1 * \operatorname{sign}\left(-j-\left(\operatorname{int}\left[\frac{i-1}{X_{2}}\right]+1\right) X_{2}+0.5\right)+1
\end{aligned}
$$

These systems of equation have been created for the number of passes up to $X 1=7$ and $X 2=6$, with an overall counter flow arrangement. After solving the above system of equations, the following series can be used to obtain changes in temperature of fluids:

$$
\begin{aligned}
& \delta T_{\sum 1}=\sum_{i=1}^{X_{2}}\left(\frac{1}{X_{1}} \sum_{i i=1}^{X_{2}} \delta T_{(i-1)\left(X_{2}+i i\right)}\right) \\
& \delta T_{\sum 2}=\frac{G_{1} c_{1} \delta T_{\sum 1}}{G_{2} c_{2}}
\end{aligned}
$$

The overall heat transfer rate:

$$
Q_{1}=G_{1} c_{1} \delta T_{\sum 1}
$$

From the above equation it can be concluded that, to determine the amount of change in flow temperature, the rate of overall heat transfer coefficient $(U b)$ should be known; this parameter is determined according to heat transfer equation:
$U_{b}=\frac{1}{h_{1}}+\frac{\delta_{w}}{k}+\frac{1}{h_{2}}$

Where $\delta_{w}$ is wall thickness $(\mathrm{m}), h_{1}$ is convection coefficient of hot fluid $\left(\mathrm{W} / \mathrm{m}^{2} \cdot \mathrm{K}\right), h_{2}$ is convection coefficient of cold fluid $\left(\mathrm{W} / \mathrm{m}^{2} \cdot \mathrm{K}\right)$, and $k$ is thermal conductivity of wall $(\mathrm{W} / \mathrm{m} \cdot \mathrm{K})$.For determining the convection coefficient $\left(h_{1}, h_{2}\right)$, the following empirical relationship is normally applied:

$N u=f(\operatorname{Re}, \operatorname{Pr})=A * \operatorname{Re}^{n} * \operatorname{Pr}^{0.4} *\left(\frac{\mu}{\mu_{w}}\right)^{0.14}$

Where

$N u=\frac{h d_{e}}{k}$

Where de is channel equivalent diameter (m).

Consider,

$\operatorname{Re}=\frac{\rho w d_{e}}{\mu}$

Where $\rho$ is density $(\mathrm{kg} / \mathrm{m} 3), \mathrm{w}$ is the velocity in the channel(m/s), $\mu$ is dynamic viscosity at flow temperature $(\mathrm{kg} / \mathrm{ms}), \mu_{w}$ is dynamic viscocity at wall temperature $(\mathrm{kg} / \mathrm{ms})$. Consider

$\operatorname{Pr}=\frac{c \mu}{k}$

Following equation is used to determine the pressure drop in single-pass PHE.

$\Delta p=\xi * \frac{l_{p}}{d_{e}} * \frac{\rho w^{2}}{2}+\Delta p_{p-c}$

Where $\Delta p_{p-c}$ is pressure drop in the PHE collector.

$\Delta p_{p-c}=1.3 * \rho * \frac{w_{p o r t}^{2}}{2}$

Pressure of single pass must be multiplied by the number of passes in order to calculate the pressure drop in multi pass PHE.

$l_{p}$ is the effective length of the plate $(\mathrm{m})$

$\mathrm{w}_{\text {portis }}$ the flow rate in the collector $(\mathrm{m} / \mathrm{s})$

$\xi$ is the friction coefficient

$\xi=\frac{B}{\operatorname{Re}^{m}}$

Least square method is used to determine the parameters of convection coefficient $(A, n)$ and theparameters of friction coefficient $(B, m)$.Geometric properties of PHE must be determined to determine these parametersin this case, Alfa Laval company's data has been used. Thegeometrical parameters of plates and inter-plate channels are given in Table 1 and the obtained parameters of correlation are given in Table 2.

\section{Plate Heat Exchanger Optimization Algorithm}

A program should be written based on this mathematical model in such a way that its answers 
meet all thermal and hydraulic demands and contain the minimum number of plates compared to other answers, so some points must be regarded to increase the accuracy of program.

(1)The physical properties that are required in the calculations are thermal conductivity wall $(K)$, specific heat of the fluid $(C)$, fluid density $(\rho)$, and liquid viscosity $(\mu)$. The average temperature had few changes by the values of $\rho, K$, and $C$, hence it is a reasonable assumption to assume them as constant. But there were wide changes in viscosity at normal temperatures. In this program, three values of the viscosity at three different temperatures are considered to consider viscosity changes: one near the inlet of channel, one near the outlet of channel, and the other one between these two.

(2) Due to the small thermal boundary layer, at the beginning of the flow entrance, heat transfer coefficient is very large. The rate of convection coefficient decreases and reaches a constant value as the flow is developing along the heat exchanger and increasing the boundary layer. The distance between the channel entrances to the location where the temperature profile no longer changes along the channel length is called the length of thermal boundary layer that can be obtained from the following equation:

Laminar flow:

$\frac{x_{f d_{3}}}{D}=0.05 \operatorname{Re}_{D} \operatorname{Pr}$

Turbulent flow:

$$
\frac{x_{f d_{3}}}{D}=10
$$

Thermal boundary layer zone is very important in determination of the heat transfer coefficients due to changes in convection coefficients along it. In this program average of convection coefficient along its channel length were used to fine changes in convection coefficient.

(3) Wang et al. has described how velocity is distributed in the channels of plate heat exchangers; velocity and pressure distribution in the channels were obtained; for example, velocity and pressure distribution for $U$-type arrangement are shown in Figures 3 and 4 . Based on these figures it is found that greater pressure difference between the inlet and outlet port in a channel causes higher rate in this channel than the other channels. Non uniform distribution of the flow causes non uniform resistance to hydraulic flow; this phenomenon is found to be more significant in horizontal rather than vertical flow and it also causes non uniformity of heat coming from the fluid. In this program, the non uniform distribution is considered by this distribution model.

Table 1: Geometric properties of Alfa laval PHE

\begin{tabular}{|c|c|c|c|c|c|c|c|}
\hline $\begin{array}{c}\text { Plate } \\
\text { type }\end{array}$ & $\delta$ & $\mathrm{D}_{\mathrm{e}}$ & $\mathrm{b}$ & $\mathrm{S}_{\mathrm{pl}}$ & $\mathrm{D}_{\text {connection }}$ & $\mathrm{S}_{\mathrm{ch}} * 10^{3}$ & $\mathrm{~L}_{\mathrm{p}}$ \\
\hline $\mathrm{M} 3$ & 24 & 48 & 100 & 0.035 & 36 & 0.24 & 320 \\
\hline $\mathrm{M} 6$ & 2 & 4 & 216 & 0.15 & 50 & 0.432 & 694 \\
\hline M6M & 3 & 6 & 210 & 0.14 & 50 & 0.63 & 666 \\
\hline
\end{tabular}

$b$ : plate width (mm).

$S_{\text {ch }}$ : cross-sectional area of each channel $\left(\mathrm{m}^{2}\right)$.

$S_{\mathrm{pl}}$ : cross-sectional area of each plate $\left(\mathrm{m}^{2}\right)$.

$\delta$ : inter-plate gap $(\mathrm{mm})$.

Table 2: Parameters of PHE

\begin{tabular}{|c|c|c|c|c|c|c|c|}
\hline $\begin{array}{c}\text { Channel } \\
\text { type }\end{array}$ & $\mathrm{B} 1$ & $\mathrm{~m} 1$ & $\mathrm{Re}$ & $\mathrm{B} 2$ & $\mathrm{~m} 2$ & $\mathrm{~A}$ & $\mathrm{~N}$ \\
\hline M3-H & 33 & 0.25 & 520 & 10.7 & 0.07 & 0.265 & 0.7 \\
\hline M3-M & 44 & 0.4 & 1000 & 5.1 & 0.1 & 0.18 & 0.7 \\
\hline M3-L & 18.8 & 0.33 & 1000 & 8.8 & 0.22 & 0.12 & 0.7 \\
\hline M6-H & 10 & 0.2 & 1250 & 2.4 & 0 & 0.25 & 0.7 \\
\hline M6-M & 9.3 & 0.3 & 930 & 2.72 & 0.12 & 0.165 & 0.7 \\
\hline M6-L & 5.1 & 0.3 & 1500 & 1.7 & 0.15 & 0.12 & 0.7 \\
\hline M6M-H & 11.7 & 0.13 & 1300 & 4.55 & 0 & 0.27 & 0.7 \\
\hline M6M-M & 5.61 & 0.16 & 2100 & 1.41 & 0 & 0.14 & 0.73 \\
\hline M6M-L & 4.23 & 0.23 & 220 & 1.88 & 0.12 & 0.11 & 0.71 \\
\hline
\end{tabular}

The main structure of the algorithm is as shown in Figure 6 and the steps of algorithm are as follows.

(1) The first step includes the design requirements to be entered, like PHE type (plate type and plate material), fluids, heat transfer rate, maximum pressure drop of two fluids, input temperatures, mass flow of the fluids, and the margin.

(2) In the second stage, the minimum number of plates is determined according to equation (22); this relation determines the maximum mass flow rate of $i$ th stream in one channel of the $j$-type according to the maximum pressure drop (this is done for three channel types of $H$, and $L$ ):

$G_{\max }=\left[\left(\frac{d_{e}}{S_{c h j} * \rho_{i} * v_{i}}\right)^{m_{j}}\right]^{1 /\left(2-m_{j}\right)} *$

$\left.\left[\begin{array}{l}2 * \\ \left(\Delta p_{i}^{0}-0.65 * X_{i} * \rho_{i} * w_{p o r t}^{2}\right) * \\ d_{e q} \rho_{i} S_{c h j}^{2} \\ *\left(l_{p} * B_{j} * X_{i}\right)^{-1}\end{array}\right)\right]^{1 /\left(2-m_{j}\right)}$

Where $\Delta p i$ is maximum allowable pressure drop pa) and Viis kinematic viscosity $(\mathrm{m} 2 / \mathrm{s})$.

(3) After determining the minimum number of allowed plates (due to pressure) in each of the channels at the third stage, the heat transfer rate of heat exchanger is determined in this specified plate number. (This step is done separately for each of three channel types.)

(4) At this stage, the program goes to step (5)if the number of plates provides the required heat of heat exchanger; otherwise, a plate is added to plates and the program goes to step (3). (This step is done separately for each of three channel types.)

(5) At this stage, the answer of each channel, which meets the requirements, is stored.

(6) In this step, optimum answer having the minimum number of plates of the three answers presented is introduced.

(7) To make the optimum answer in multipass PHEs mode loops are used; in the 7th stage, the loop 
increases the number of cold fluid passes and thereby optimum answer is determined in several different modes of multipass.

(8)This step is similar to Step (7), except that it increases the hot fluid passes.

(9) In Stage (9), the answer containing the minimum number of plate of all the different states (single-pass and multipass), is introduced as best answer of the program. The results include the number of plates, type of channel, and pressure drop of fluids (Figure 5)

Table 3: Case study data for PHE for M3 channels

\begin{tabular}{|c|c|c|c|c|c|c|c|}
\hline \multicolumn{2}{|c|}{ Case study 1} & \multicolumn{2}{|c|}{ Case study 2} & \multicolumn{2}{|c|}{ Case study 3} & \multicolumn{2}{|c|}{ Case study 4} \\
\hline \multicolumn{2}{|c|}{$\mathrm{Th}_{\mathrm{i}}=60^{\circ} \mathrm{C}$} & \multicolumn{2}{|c|}{$\mathrm{Th}_{\mathrm{i}}=60^{\circ} \mathrm{C}$} & \multicolumn{2}{|c|}{$\mathrm{Th}_{\mathrm{i}}=60^{\circ} \mathrm{C}$} & \multicolumn{2}{|c|}{$\mathrm{Th}_{\mathrm{i}}=60^{\circ} \mathrm{C}$} \\
\hline \multicolumn{2}{|c|}{$\mathrm{Tc}_{\mathrm{i}}=30^{\circ} \mathrm{C}$} & \multicolumn{2}{|c|}{$\mathrm{Tc}_{\mathrm{i}}=30^{\circ} \mathrm{C}$} & \multicolumn{2}{|c|}{$\mathrm{Tc}_{\mathrm{i}}=20^{\circ} \mathrm{C}$} & \multicolumn{2}{|c|}{$\mathrm{Tc}_{\mathrm{i}}=20^{\circ} \mathrm{C}$} \\
\hline \multicolumn{2}{|c|}{$\Delta p_{i}^{o}=70 \mathrm{kpa}$} & \multicolumn{2}{|c|}{$\Delta p_{i}^{o}=100 \mathrm{kpa}$} & \multicolumn{2}{|c|}{$\Delta p_{i}^{o}=70 \mathrm{kpa}$} & \multicolumn{2}{|c|}{$\Delta p_{i}^{o}=100 \mathrm{kpa}$} \\
\hline \multicolumn{2}{|c|}{$\mathrm{G}_{1}=0.50 \mathrm{~kg} / \mathrm{s}$} & \multicolumn{2}{|c|}{$\mathrm{G}_{1}=2.0 \mathrm{~kg} / \mathrm{s}$} & \multicolumn{2}{|c|}{$\mathrm{G}_{1}=1.25 \mathrm{~kg} / \mathrm{s}$} & \multicolumn{2}{|c|}{$\mathrm{G}_{1}=0.66 \mathrm{~kg} / \mathrm{s}$} \\
\hline \multicolumn{2}{|c|}{$\mathrm{G}_{1}=0.25 \mathrm{~kg} / \mathrm{s}$} & \multicolumn{2}{|c|}{$\mathrm{G}_{1}=0.50 \mathrm{~kg} / \mathrm{s}$} & \multicolumn{2}{|c|}{$\mathrm{G}_{1}=0.75 \mathrm{~kg} / \mathrm{s}$} & \multicolumn{2}{|c|}{$\mathrm{G}_{1}=1.0 \mathrm{~kg} / \mathrm{s}$} \\
\hline \multicolumn{2}{|c|}{ Heat load } & \multicolumn{2}{|c|}{ Heat load } & \multicolumn{2}{|c|}{ Heat load } & \multicolumn{2}{|c|}{ Heat load } \\
\hline No. & $\mathrm{Q}(\mathrm{kW})$ & No. & $\mathrm{Q}(\mathrm{kW})$ & No. & $\mathrm{Q}(\mathrm{kW})$ & No. & $\mathrm{Q}(\mathrm{kW})$ \\
\hline 1 & 16.69 & 1 & 21.49 & 1 & 50.1 & 1 & 98.1 \\
\hline 2 & 27.14 & 2 & 16.29 & 2 & 72.01 & 2 & 112.7 \\
\hline 3 & 29.02 & 3 & 29.63 & 3 & 81.4 & 3 & 135.7 \\
\hline 4 & 29.45 & 4 & 30.78 & 4 & 101.4 & 4 & 155.3 \\
\hline 5 & 30.48 & 5 & 31.1 & 5 & 107.4 & 5 & 173.7 \\
\hline 6 & 30.9 & 6 & 31.2 & 6 & 113.4 & 6 & 177.9 \\
\hline 7 & 31.14 & 7 & 31.28 & 7 & 117.3 & 7 & 181.7 \\
\hline 8 & 31.27 & 8 & 31.31 & 8 & 118.4 & 8 & 187.7 \\
\hline
\end{tabular}

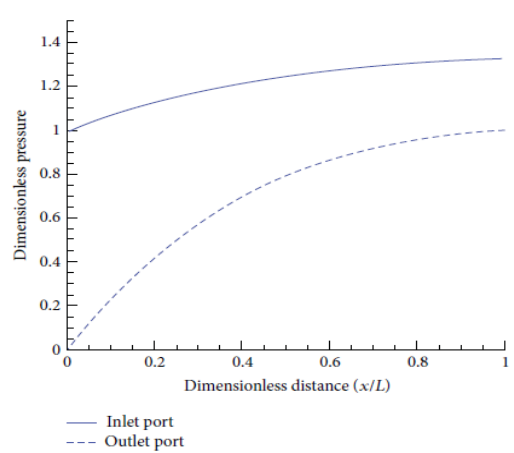

Figure 3: pressure distribution in single pass heat exchanger channels with $U$ arrangement

Table 4: Case study data for PHE for M6 channels

\begin{tabular}{|c|c|c|c|c|c|c|c|}
\hline \multicolumn{2}{|c|}{ Case study 1} & \multicolumn{2}{|c|}{ Case study 2} & \multicolumn{2}{|c|}{ Case study 3} & \multicolumn{2}{|c|}{ Case study 4} \\
\hline \multicolumn{2}{|c|}{$\mathrm{Th}_{\mathrm{i}}=80^{\circ} \mathrm{C}$} & \multicolumn{2}{|c|}{$\mathrm{Th}_{\mathrm{i}}=70^{\circ} \mathrm{C}$} & \multicolumn{2}{|c|}{$\mathrm{Th}_{\mathrm{i}}=70^{\circ} \mathrm{C}$} & \multicolumn{2}{|c|}{$\mathrm{Th}_{\mathrm{i}}=80^{\circ} \mathrm{C}$} \\
\hline \multicolumn{2}{|c|}{$\mathrm{Tc}_{\mathrm{i}}=30^{\circ} \mathrm{C}$} & \multicolumn{2}{|c|}{$\mathrm{Tc}_{\mathrm{i}}=20^{\circ} \mathrm{C}$} & \multicolumn{2}{|c|}{$\mathrm{TC}_{\mathrm{i}}=20^{\circ} \mathrm{C}$} & \multicolumn{2}{|c|}{$\mathrm{Tc}_{\mathrm{i}}=30^{\circ} \mathrm{C}$} \\
\hline \multicolumn{2}{|c|}{$\Delta p_{i}^{O}=80 \mathrm{kpa}$} & \multicolumn{2}{|c|}{$\Delta p_{i}^{o}=100 \mathrm{kpa}$} & \multicolumn{2}{|c|}{$\Delta p_{i}^{o}=100 \mathrm{kpa}$} & \multicolumn{2}{|c|}{$\Delta p_{i}^{o}=80 \mathrm{kpa}$} \\
\hline \multicolumn{2}{|c|}{$\mathrm{G}_{1}=2.0 \mathrm{~kg} / \mathrm{s}$} & \multicolumn{2}{|c|}{$\mathrm{G}_{1}=1.25 \mathrm{~kg} / \mathrm{s}$} & \multicolumn{2}{|c|}{$\mathrm{G}_{1}=0.9 \mathrm{~kg} / \mathrm{s}$} & \multicolumn{2}{|c|}{$\mathrm{G}_{1}=1.33 \mathrm{~kg} / \mathrm{s}$} \\
\hline \multicolumn{2}{|c|}{$\mathrm{G}_{1}=2.5 \mathrm{~kg} / \mathrm{s}$} & \multicolumn{2}{|c|}{$\mathrm{G}_{1}=3.0 \mathrm{~kg} / \mathrm{s}$} & \multicolumn{2}{|c|}{$\mathrm{G}_{1}=5 \mathrm{~kg} / \mathrm{s}$} & \multicolumn{2}{|c|}{$\mathrm{G}_{1}=4.0 \mathrm{~kg} / \mathrm{s}$} \\
\hline \multicolumn{2}{|c|}{ Heat load } & \multicolumn{2}{|c|}{ Heat load } & \multicolumn{2}{|c|}{ Heat load } & \multicolumn{2}{|c|}{ Heat load } \\
\hline $\begin{array}{l}\mathrm{N} \\
\mathrm{o} .\end{array}$ & $\mathrm{Q}(\mathrm{kW})$ & No. & $\mathrm{Q}(\mathrm{kW})$ & No. & $\mathrm{Q}(\mathrm{kW})$ & No. & $\mathrm{Q}(\mathrm{kW})$ \\
\hline 1 & 177.6 & 1 & 319.3 & 1 & 480.1 & 1 & 359.3 \\
\hline 2 & 224.6 & 2 & 375.7 & 2 & 555.4 & 2 & 451.1 \\
\hline 3 & 249.6 & 3 & 402.8 & 3 & 667.9 & 3 & 512.9 \\
\hline 4 & 253.8 & 4 & 434.5 & 4 & 772.4 & 4 & 534.6 \\
\hline 5 & 260 & 5 & 442.9 & 5 & 793.3 & 5 & 570.3 \\
\hline 6 & 260.3 & 6 & 464.9 & 6 & 812.1 & 6 & 577.2 \\
\hline 7 & 260.6 & 7 & 473 & 7 & 865.5 & 7 & 593 \\
\hline 8 & 260.9 & 8 & 487.3 & 8 & 883.4 & 8 & 599.7 \\
\hline
\end{tabular}

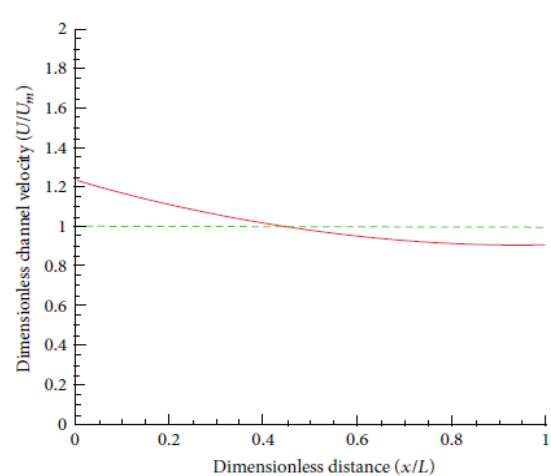

Figure 4: Velocity distribution in single pass heat exchanger channels with $U$ arrangement

Table 5: Case study data for PHE for M6M channels

\begin{tabular}{|c|c|c|c|c|c|c|c|}
\hline \multirow{2}{*}{\multicolumn{2}{|c|}{ Case study 1}} & \multicolumn{2}{|c|}{ Case study 2} & \multicolumn{2}{|c|}{ Case study 3} & \multicolumn{2}{|c|}{ Case study 4} \\
\hline & & \multicolumn{2}{|c|}{$\mathrm{Th}_{\mathrm{i}}=70^{\circ} \mathrm{C}$} & \multicolumn{2}{|c|}{$\mathrm{Th}_{\mathrm{i}}=80^{\circ} \mathrm{C}$} & \multicolumn{2}{|c|}{$\mathrm{Th}_{\mathrm{i}}=70^{\circ} \mathrm{C}$} \\
\hline \multicolumn{2}{|c|}{$\mathrm{Tc}_{\mathrm{i}}=20^{\circ} \mathrm{C}$} & \multicolumn{2}{|c|}{$\mathrm{Tc}_{\mathrm{i}}=20^{\circ} \mathrm{C}$} & \multicolumn{2}{|c|}{$\mathrm{Tc}_{\mathrm{i}}=20^{\circ} \mathrm{C}$} & \multicolumn{2}{|c|}{$\mathrm{Tc}_{\mathrm{i}}=20^{\circ} \mathrm{C}$} \\
\hline \multicolumn{2}{|c|}{$\Delta p_{i}^{o}=90 \mathrm{kpa}$} & \multicolumn{2}{|c|}{$\Delta p_{i}^{o}=100 \mathrm{kpa}$} & \multicolumn{2}{|c|}{$\Delta p_{i}^{o}=100 \mathrm{kpa}$} & \multicolumn{2}{|c|}{$\Delta p_{i}^{o}=90 \mathrm{kpa}$} \\
\hline \multicolumn{2}{|c|}{$\mathrm{G}_{1}=0.50 \mathrm{~kg} / \mathrm{s}$} & \multicolumn{2}{|c|}{$\mathrm{G}_{1}=0.8 \mathrm{~kg} / \mathrm{s}$} & \multicolumn{2}{|c|}{$\mathrm{G}_{1}=1.25 \mathrm{~kg} / \mathrm{s}$} & \multicolumn{2}{|c|}{$\mathrm{G}_{1}=1.2 \mathrm{~kg} / \mathrm{s}$} \\
\hline \multicolumn{2}{|c|}{$\mathrm{G}_{1}=2.0 \mathrm{~kg} / \mathrm{s}$} & \multicolumn{2}{|c|}{$\mathrm{G}_{1}=3.0 \mathrm{~kg} / \mathrm{s}$} & \multicolumn{2}{|c|}{$\mathrm{G}_{1}=5.0 \mathrm{~kg} / \mathrm{s}$} & \multicolumn{2}{|c|}{$\mathrm{G}_{1}=6.0 \mathrm{~kg} / \mathrm{s}$} \\
\hline \multicolumn{2}{|c|}{ Heat load } & \multicolumn{2}{|c|}{ Heat load } & \multicolumn{2}{|c|}{ Heat load } & \multicolumn{2}{|c|}{ Heat load } \\
\hline $\begin{array}{l}\mathrm{N} \\
\mathrm{o}\end{array}$ & $\mathrm{Q}(\mathrm{kW})$ & No. & $\mathrm{Q}(\mathrm{kW})$ & No. & $\mathrm{Q}(\mathrm{kW})$ & No. & $\mathrm{Q}(\mathrm{kW})$ \\
\hline 1 & 200.4 & 1 & 245 & 1 & 532.6 & 1 & 420.9 \\
\hline 2 & 271.5 & 2 & 413.3 & 2 & 602.6 & 2 & 592.6 \\
\hline 3 & 293.2 & 3 & 442.1 & 3 & 705.8 & 3 & 706.3 \\
\hline 4 & 307.4 & 4 & 479.8 & 4 & 790.6 & 4 & 762.7 \\
\hline 5 & 323.8 & 5 & 538.7 & 5 & 808.8 & 5 & 816 \\
\hline 6 & 325.9 & 6 & 550 & 6 & 825.9 & 6 & 831.7 \\
\hline 7 & 327.1 & 7 & 563.8 & 7 & 891.6 & 7 & 842.7 \\
\hline 8 & 329.9 & 8 & 588.1 & 8 & 909.4 & 8 & 911.8 \\
\hline
\end{tabular}

\section{Results}

Program results should be evaluated by correct result to determine the accuracy of the program. Program's result for water is evaluated for a series of Alfa Laval heat exchangers (M3, M6, and M6M) in twelve case studies. Tables 3,4 , and 5 gives the case studies data. The data involves initial temperature of hot and cold fluids, requirement heat load, maximum allowable pressure drop, and plate type. The difference between the results from the written program and result of CAS200software [16] is shown as the error percentage of heat transfer area in the range of heat loads. As a matter of fact, the accuracy of the program is investigated in wide range of plate numbers because of positive correlation between heat load and number of plates. The error percentage is shown in Figures 7, 8, and 9. The general trend of the graphs is inflow heat loads (small number of plates).Error percentage is negative and, by increasing the heat load, it increases. The program's error in high heat loads compared to lower ones has more accuracy. In addition, the error rate decreases as the fluid flow rate increases.

Causes of an error in the program are divided into two Categories:

(1) The thermal effect of the start and end plates: endplate has a substantial effect on heat transfer rates 
and reduces the heat capacity for PHE with small plates. Considering the effect of this factor on program complicated model is required but in general method which is based on trial and error it is possible to regard it. Figure 10 shows a comparison between the result of trial and error method which is based on data obtained by Kandlikar and Shah and CAS200 software for case study 1.
(2) Transverse distribution of flow inside channels: this phenomenon occurs due to the small size of both entry and end port of the plate in comparison with the width of the main heat transfer area leading to transverse temperature profile in channels. Though the transverse distribution in the plate heat exchanger design is an important issue, it is difficult to estimate and calculate it.

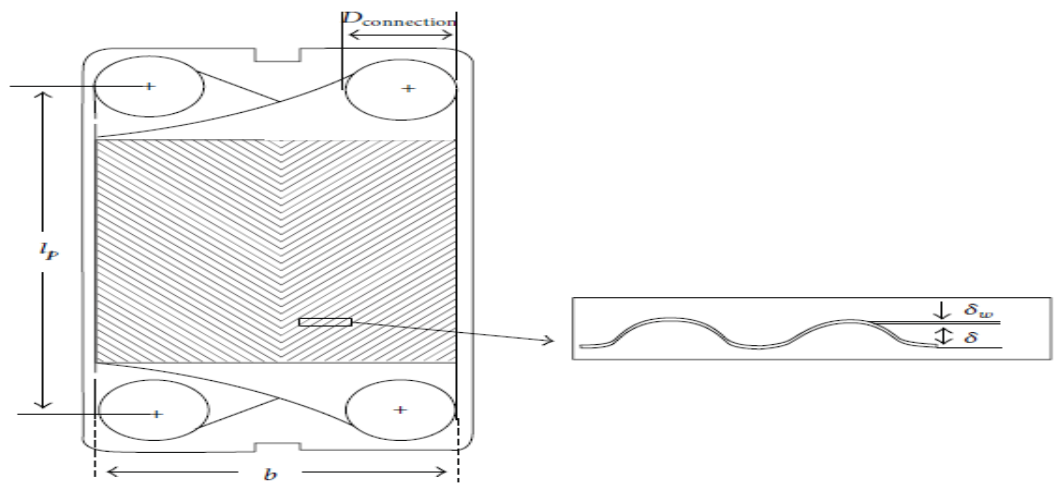

Figure 5: Plate dimensions

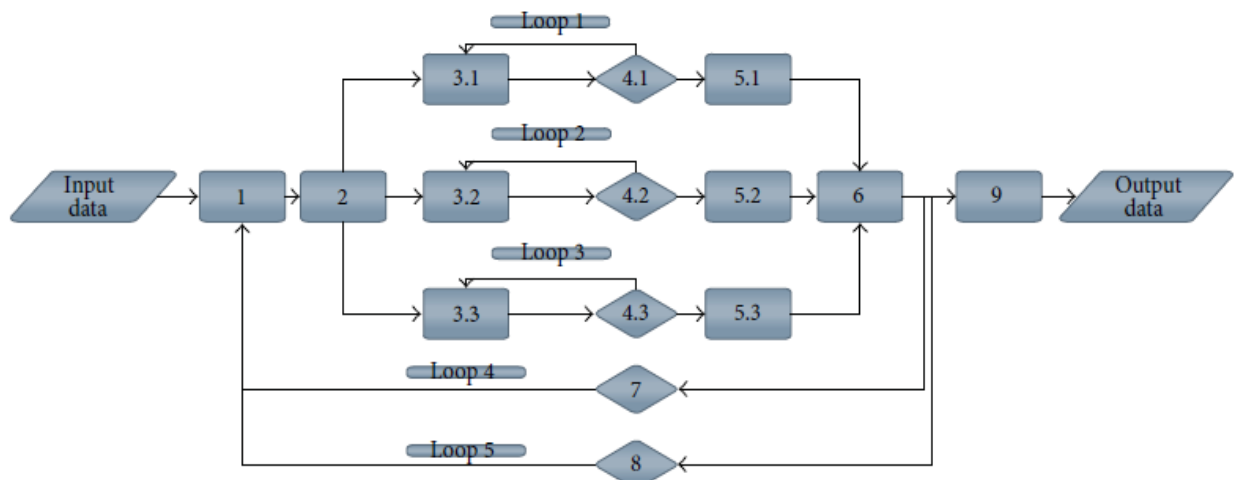

Figure 6: Flow chart for algorithm

\section{Conclusion}

In this paper, a program based on mathematical model proposed by Arsenyeva et al. in order to find a PHE which not only meets thermal and hydraulic demand but also has the least number of plates was presented. The effects of mal distribution and thermal boundary layer on PHE were considered. The accuracy of the answer of case studies was checked by comparing solution with the correct answer using CAS200 software. The results shows that for a small number of plates due to the effect of the start and end plates and transverse distribution, the heat capacity of PHE is less than the excepted value, thus resulting in negative percent of error. The effect of these factors decreases and the accuracy of program enhances as the number of plates increases. However the accuracy of program is acceptable. A more advanced algorithm is needed to achieve the upper accuracy. Further improvement can be made in future work by consideration of other factors such as end plate effect, transverse distribution, and fouling.

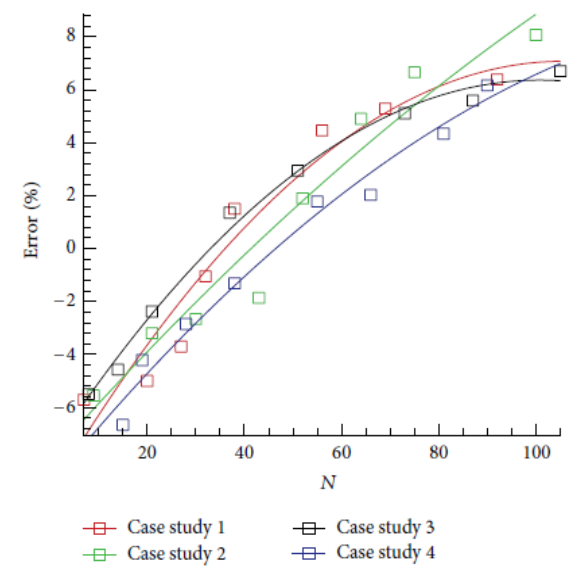

Figure 7: Error percentage of program results with the optimum results for PHE formed by different sets of M3 channels 


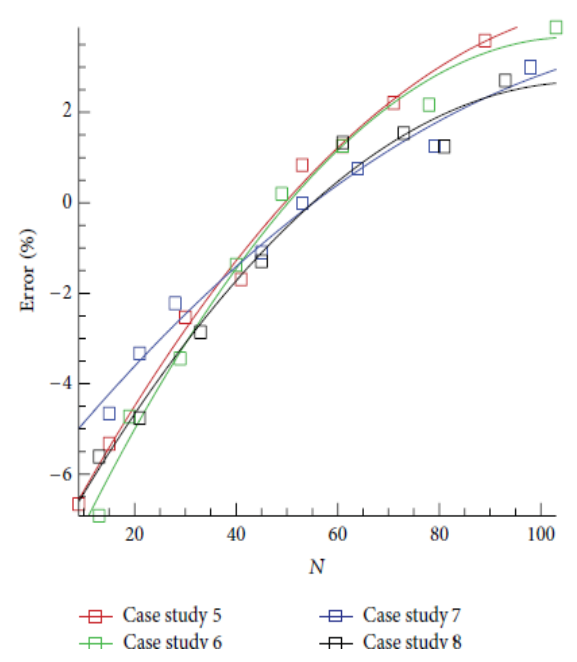

Figure 8: Error percentage of program results with the optimum results for PHE formed by different sets of M6 channels.

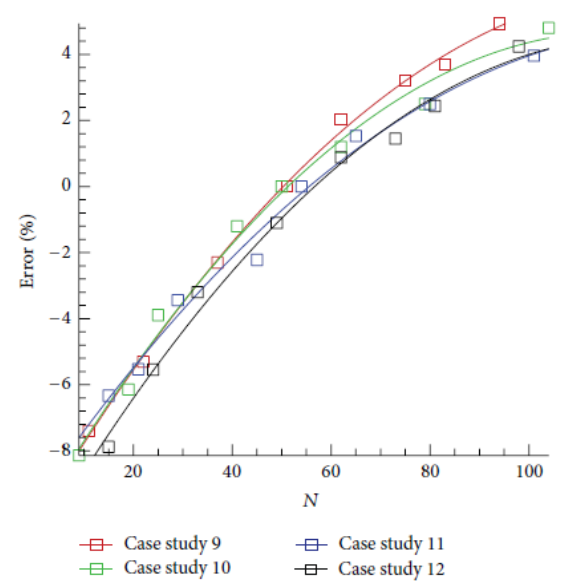

Figure 9: Error percentage of program results with the optimum results for PHE formed by different sets of M6M channels.

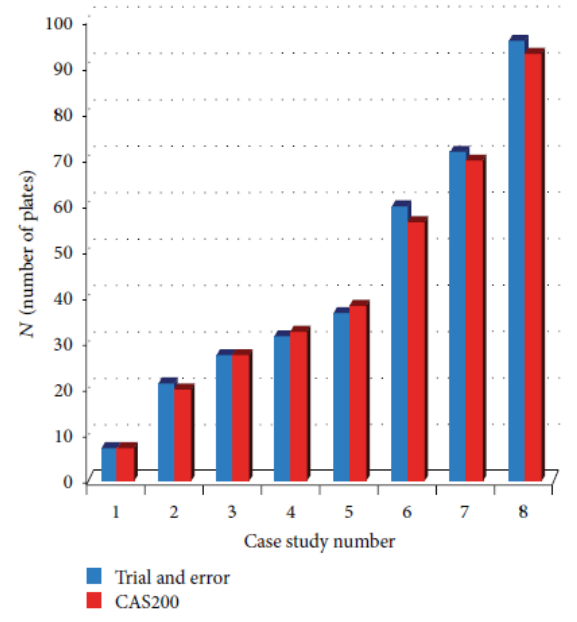

Figure 10: Comparison of results for case study 1.

\section{References}

R. K. Shah and A. S. Wanniarachchi(1991) Plate heat exchanger design theory, Industrial Heat Exchangers, J.-M. Buchlin,Ed., vol. 4 of Lecture Series, von Karman Institute for Fluid Dynamics, Sint-Genesius-Rode, Belgium.

W. W. Focke, J. Zachariades, and I. Olivier (1985) The effect of the corrugation inclination angle on the thermohydraulic performance of plate heat exchangers, International Journal of Heat and Mass Transfer, vol. 28, no. 8, pp. 1469-1479.

B. Prabhakara Rao, P. Krishna Kumar, and S. K. Das (2002), Effect of flow distribution to the channels on the therma performance of a plate heat exchanger, Chemical Engineering and Processing: Process Intensification, vol. 41, no. 1, pp. 49-58.

T. F. Yee, I. E. Grossmann, and Z. Kravanja (1990), Simultaneous optimization models for heat integration-I. Area and energy targeting and modeling of multi-stream exchangers, Computers \& Chemical Engineering, vol. 14, no. 10, pp. 11511164.

L.Wang and B. Sund'en (2003) Optimal design of plate heat exchangers with and without pressure drop specifications, Applied Thermal Engineering, vol. 23, no. 3, pp. 295-311.

K. Park, D.-H. Choi, and K.-S. Lee (2004) Optimum design of plate heat exchanger with staggered pin arrays, Numerical Heat Transfer; Part A: Applications, vol. 45, no. 4, pp. 347-361.

J. A.W. Gut and J. M. Pinto (2004)Optimal configuration design for plate heat exchangers,International Journal of Heat and Mass Transfer, vol. 47, no. 22, pp. 4833-4848.

G. Kanaris, A. A. Mouza, and S. V. Paras (2009) Optimal design of a plate heat exchanger with undulated surfaces, International Journal of Thermal Sciences, vol. 48, no. 6, pp. 1184-1195.

M. R. Hajmohammadi, M. R. Salimpour, M. Saber, and A. Campo (2013) Detailed analysis for the cooling performance enhancement of a heat source under a thick plate,Energy Conversion and Management, vol. 76, pp. 691-700.

M. R. Hajmohammadi, M. Moulod, O. J. Shariatzadeh, and A. Campo (2014) Effects of a thick plate on the excess temperature of iso-heat flux heat sources cooled by laminar forced convection flow: conjugate analysis, Numerical Heat Transfer, Part A: Applications, vol. 66, no. 2, pp. 205-216.

M. R. Hajmohammadi, A. Campo, S. S. Nourazar, and A. M. Ostad (2013) Improvement of forced convection cooling due to the attachment of heat sources to a conducting thick plate, Journal of Heat Transfer, vol. 135, no. 12, Article ID124504.

M. R. Hajmohammadi, A. Pouzesh, and S. Poozesh (2012) Controlling the heat flux distribution by changing the thickness of heated wall, Journal of Basic and Applied Sciences, vol. 2, no. 7, pp. 7270-7275.

O. P. Arsenyeva, L. L. Tovazhnyansky, P. O. Kapustenko, and G. L. Khavin (2011) Optimal design of plate-and-frame heat exchangers for efficient heat recovery in process industries, Energy, vol. 36, no. 8, pp. 4588-4598.

F. P. Incropera, A. S. Lavine, and D. P. DeWitt (2011)Fundamentals of Heat and Mass Transfer, JohnWiley \& Sons.

L.Wang, B. Sund'en, and R. M.Manglik (2007)Plate Heat Exchangers: Design, Applications and Performance, vol. 11,Wit Press.

Energo Soft, CAS200, http://energosoft.info/soft teplotex 21 30.html.

S. G. Kandlikar and R. K. Shah (1989) Multipass plate heat exchangers-effectiveness-NTU results and guidelines for selecting pass arrangements, Journal of Heat Transfer, vol. 111 no. 2 , pp. 300-313. 